AECD-3940

\author{
ARGONNE ATIONAL LABORATORY \\ D. O. B ox 5207 \\ Chicago 80, Illinois
}

Date Declassified: January 5, 1956

\title{
OAK RIDGE STATIC AUTOCLAVE \\ WATER DECOMPOSITION TEST
}

by

J, R. Humphreys, Jr., E, L. Abers, P. E. Brown and Associates

May 1, 1951

Naval Reactor Division

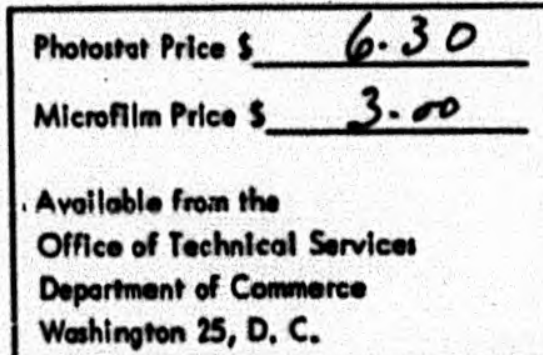

Operated by The University of Chicago under

Contract $W-31-109-e n g-38$ 


\section{TABLE OF CONTENTS}

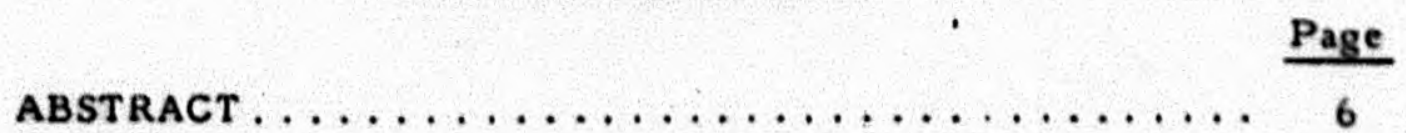

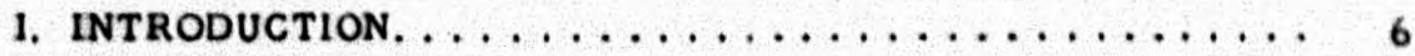

II. GENERAL DESCRIPTION OF TEST AND APPARATUS . . . . 7 7

A. Experimental Facilities and Methods ........ 7

1. Operational Equipment ............. 7

2. Steady State Operation . . . . . . . . . . 8

3. Recombination Operation. ............ 8

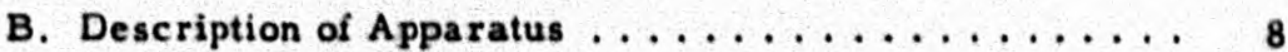

1. Flux Converter ................ 8

2. Autoclave and Valving. . . . . . . . . . . 9

3. Sample Ampoule and Sampling Technique........ 9

4. Instrumentation. ................ 10

a. Measurement of Liquid and Vapor

Temperatures in the Autoclave. ......... 11

b. Automatic Temperature Control of Water

in the Autoclave................. 11

c. Measurement of System Pressure........ 12

d. Measurement of the Temperature in

Converter and Coolant Streams ......... 12

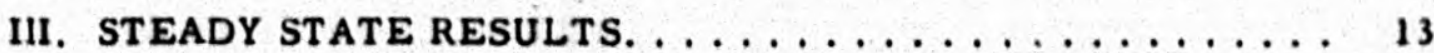

A. Constant Temperature Steady State Results . . . . . . 14

B. Variable Temperature Steady State kesults ........ 14

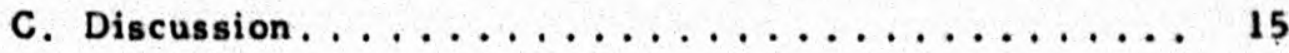

IV. RECOMBINATION RESULTS $\ldots \ldots \ldots \ldots \ldots \ldots \ldots \ldots$

A. Effect of Temperature on Recombination . . . . . 17

B. Recombination as a Function of Flux, ......... 19

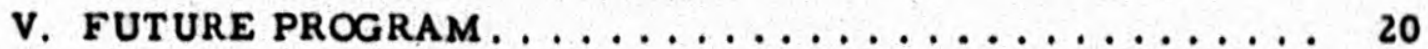




\section{LIST OF FICURES}

\section{Page}

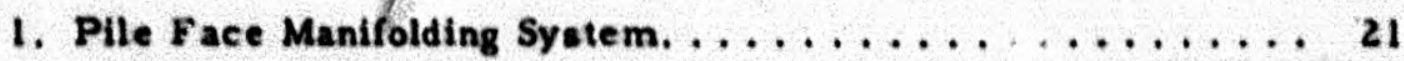

2. Oak Ridge Flux Converter $\ldots \ldots \ldots \ldots \ldots \ldots \ldots$

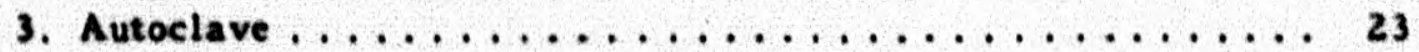

4. Photograph - Autoclave and Converter ... . . . . . 24

5. Photograph - Autoclave and Converter Instruments . . . . 25

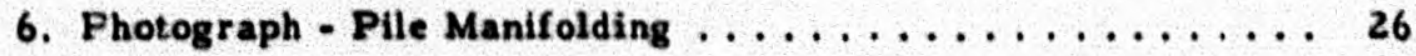

7. Sample Ampoule. . . . . . . . . . . . . . 27

8. General Instrumentation - Schematic Layout . . . . . . 28

9. Photograph - Instrument Panel . . . . . . . . . . . 29

10. Automatic Temperature Control Circuit . . . . . . . . 30

11. Pressure Recorder - Wiring Diagram . . . . . . . . 31

12. Effect of Temperature on Recombination . . . . . . . 32

13. Effect of Temperature on Recombination . . . . . . . . 33

14. Fill No. 18 - Recombination - $202.5 F \ldots \ldots \ldots$

15. Fill No. $17-305 \mathrm{~F}$ - Combination of $\mathrm{H}_{2}+\mathrm{O}_{2}-$ Variation

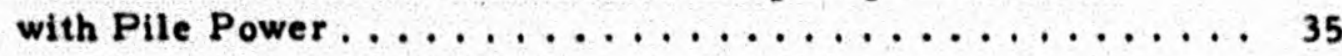

16. Effect of Flux on Recombination ............. 36

17. Effect of Flux on Recombination . . . . . . . . . 37 


\section{LIST OF TABLES}

Page

1. Saturation Data for Water (200 to 500F) and Rate of Change of Pressures with Temperature . . . . . . . . . 10

II. Effec of Pile Flux on Dissociation Pressure at Constant Temperature . . . . . . . . . . . . . . . . 14

III. Effect of Pile Flux on Dissociation Pressure for Several

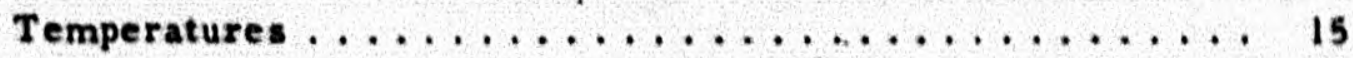

IV. Variation in Published Vapor Pressure Data for Water . . . . 16

v. Rate of Combination of Hydrogen and Oxygen as a Function of Temperature . . . . . . . . . . . . . 18

V1. Operational Variations in the Effect of Flux Density on Combination ....................... 20 
OAK RIDGE STATIC AUTOCLAVE WATER DECOMPOSITION TEST

\section{ABSTRACT}

Steady state decomposition product partial pressures of water exposed to an epithermal neutron flux of about $2 \times 10^{\prime \prime}$, at $235 \mathrm{~F}$, were 0.4 to $0.65 \mathrm{psi}$.

Recombination studies were made by adding hydrogen and oxygen gases to water under irradiation at different temperature and flux levels. The data show a significant effect of temperature on the rate of pressure drop of the added hydrogen and oxygen. In operating at two flux levels, $1.2 \times 10^{11}$ and $2.0 \times 10^{11}$, no difference in the rate of pressure drop with flux could be detected with the instrumentation on the test apparatus.

\section{INTRODUCTION}

An important consideration in the design of a water cooled closed system reactor is the amount of decomposition products which may build up in water under irradiation. The gaseous hydrogen and oxygen thus formed may give rise to local boiling within the reactor resulting in hot spots being formed on the fuel plates and also leat to density variation in the moderator. In addition to the heat transfer and control problems arising from local boiling, the presence of dissolved oxygen in the water introduces a corrosion problem.

Previous investigators have shown that the concentrations of the decomposition products of pure water tue to irradiation will rise to a steady state level. At this point, the back reaction of the decomposition products is equal in rate to the breakdown of the water by radiation. The most comprehensive previous work reported on the temperature effect on the decomposition and recombination of water under irradiation was Allen's quartz ampoule experiments in the $X-10$ pile. (1) This work showed that the back reaction is very sensitive to the presence of impurities in the water and varies with temperature. While Allen's temperature effect investigation was limited in range, his results indicate a lowering of steady state concentrations with increasing temperatures in the range of $100 \mathrm{~F}$ to $340 \mathrm{~F}$. 
L. W. Fromm ${ }^{(2)}$ worked at higher temperatures and obtained data substantiating this lowering of steady state decomposition product pressure with increasing temperature for the range $350 \mathrm{~F}$ to $450 \mathrm{~F}$.

The irradiation of initially dry hydrogen and oxygen gas mixtures was investigated by $A$. $O$. Allen et al. (1) to determine the degree of back reaction in the gas phase. Electrolytic mixtures of hydrogen and oxygen gases were irradiated in the $\mathrm{X}-10$ pile for 20 to 56 hours at $110 \mathrm{C}$ to $150 \mathrm{C}$. The results, however, were too limited for an analysis of the tecombination of hydrogen and oxigen gases.

Since this was the only pile irradiation work previously reported, and at lower temperatures than this investigation would eneompass, it was decided to devote a large part of this test to the investigation of the recombination reaction. The purposes of the Oak Ridge Static Autoclave Decomposition Test were:

1. To determine steady state concentrations of gaseous decomposition products of pure water under irradiation in the $\mathrm{X}-\mathrm{r}^{\circ} \mathrm{O}$ reactor at temperatures varying from $200 \mathrm{~F}$ to $500 \mathrm{~F}$.

2. To determine the effect of temperature and flux intensity on rate of combination of hydrogen and oxygen gases added to pure water.

3. To gain qualitative information and operational experience for a subsequent test to be made in the Chalk River reactor.

\section{GENERAL DESCRIPTION OF TEST AND EQUIPMENT}

\section{A. Experimental Facilities and Methods}

\section{Operational Equipment}

The apparatus used in this experimental program consisted of a type 347 stainless steel autoclave with a capacity of $205 \mathrm{cc}$. Sampling lines, for both liquid and vapor phases, were mounted in the autoclave. A utoclave temperature was controlled by a vapor phase platinum resistance thermometer as the control element for a saturable reactor which regulated the heat input to an immersion heater in the liquid phase of the autoclave. Figure 1 illustrates the schematic layout of the test equipment.

A flux converter, containing five pounds of natural uranium, was placed around the autoclave to increase the epithermal neutron flux. The autoclave and uranium fiux converter were installed in hole 52 of the $X-10$ reactor at ORNL. 


\section{Steady State Operation}

The apparatus was operated in two ways to obtain steady state decomposition product partial pressures. In one method, the autoclave was charged with pure water for each temperature level and the system was brought to thermal equilibrium at the test temperature with the pile shut down, and maintaining this test temperature, the system pressure. rise with pile startup was then recorded.

In the second method equilibrium system pressures were determined at several temperature points on a water sample with the pile off and changes in the equilibrium pressures at the se temperature points were then determined with the pile on.

\section{Recombination Operation}

In general, the recombination runs were made by adding hydrogen and oxygen gases to the steady state conditions of a pure water sample at the test temperature. For the higher temperatures (above 300F) it was necessary to drop the system temperature, after establishing the pure water steady state value, to reduce the system pressure for the gas additions since the available equipment could not inject gases at pressures above 60 psig. Following the gas additions the system temperature was returned to the test value as quickly as possible and pressure readings taken at the test temperature until a steady state pressure was established.

In some runs it was possible to add the hydrogen and oxygen gases and establish thermal steady state in the system with the pile off. By noting the system pressure drop on pile startup, the effect of pile flux was observed.

\section{B. Description of Apparatus}

\section{Flux Converter}

The flux converter used in the experiment was an aluminum cylinder $3-3 / 4$ in. O.D. by $2-1 / 16$ in. I.D. by 12 in. long containing five pounds of natural uranium distributed in 8 slugs around the cylinder as shown in Figure 2. Counter-current cooling passages were drilled between the slugs for water or air cooling. The converter was estimated to have increased the epithermal flux by a factor of between 2 and 2.25. Two thermocouple wells were drilled into the aluminum walls and one through an end plug adjacent to a slug for temperature monitoring. The coolant flow was so regulated that the converter temperature never exceeded $300 \mathrm{~F}$. 


\section{Autoclave and Valving}

The $1-7 / 8$ in. O.D. by $12 \mathrm{in.}$ long autoclave was constructed of type 347 stainless steel for a design pressure of 42.00 psi (with a safety factor of 4) and had a capacity of $205 \mathrm{cc}$. Details of the assembly are shown in Figure 3. Type 347 stainless steel sampling lines, 1/8 in. O.D. by $1 / 16$ in. 1.D. were provided for both liquid and vapor phases. Each of the sample lines was $20 \mathrm{ft}$ in length and had a capacity of $\$ 2 \mathrm{cc}$. Immersion wells were located in the liquid phase of the autoclave for a platinum resistance thermometer, a nichrome heater and a 30 gage iron constantan thermocouple. An additional well was placed in the vapor.phase for a second platinum resistance thermometer. Figures 4 and 5 are photographs of the assembled autoclave and surrounding flux converter.

The type 347 stainless steel pile face manifolding system, Figures 1 and 6 , consisted of liquid and vapor phase headers for filling. sampling, purging and gas addition. The liquid phase header had connections to a sampling valve, pressure recorder, pressure gage, a 2400 psi rupture disc and to the hot drain. The vapor phase header had connections to a sampling valve, a 2400 psi rupture disc to the hot drain, and the water charger.

The charger consisted of a type 347 stainless steel autoclave of $264 \mathrm{cc}$. capacity heated by an external heating coil. A pressure gage and a 2400 psi rupture disc were mounted on the charger.

\section{Sample Ampoule and Sampling Technique}

The autoclave samples were retained in small glass ampoules illustrated in Figure 7. The sampling procedure was as follows:

(1) Evacuation of the sample ampoule using a vacuum diffusion pump.

(2) Attachment of the ampoule to the sampling line of the system with a small length of Tygon tubing to the three-way stopcock in position 1 .

(3) Opening of the sampling valve on the system until a specified amount of water sample was discharged through the by-pass (approximately $20 \mathrm{cc}$.).

(4) Turning three-way stopcock to position II until the ampoule was about 90 per cent filled and then turned back to position $\mathrm{i}$.

The ampoule was thus left with a slight vacuum to prevent leakage of the gases through the stopcocks. 
Samples of the liquid phase were taken after each run with some samples taken during a run at different temperature levels or before gas additions were made. Samples were analyzed on the vacuum type analysers used in the Argonne Pilot Channel tests at Oak Ridge. The results of the gas analyses were inconclusive since it was observed that slugs of liquid and gas were collected in the sampling ampoules; duplicate samples were inconsistent and nonhomogeneous in distribution of $\mathrm{g}$ as and liquid.

\section{Instrumentation}

The instrumentation for the measurement of both temperature and pressure variations requires precision and sensitivity, particularly for temperatures over $300 \mathrm{~F}$. Table 1 illustrates the instrumental precision needed to detect a small ( 1 to $3 \mathrm{psi}$ ) decomposition product pressure change in a system pressure range of 11.5 to $680 \mathrm{psia}$.

TABLE 1 - SATURATION DATA FOR WATER (200 TO 500F) AND

RATE OF CHANGE OF PRESSURES WITH TEMPERATURE

(KEENAN AND KEYES - PROPERTIES OF STEAM)

\begin{tabular}{|c|c|c|}
\hline $\begin{array}{c}\text { Temperature } \\
F\end{array}$ & $\begin{array}{c}\text { Pressure } \\
\text { psia }\end{array}$ & psi/F \\
\hline 200 & 11.5 & 0.3 \\
300 & 67.0 & 1.0 \\
400 & 247.3 & 2.9 \\
500 & 680.8 & 6.0 \\
\hline
\end{tabular}

For example, at the $400 \mathrm{~F}$ point, an error of $0.1 \mathrm{~F}$ in reading the temperature would result in a $0.29 \mathrm{psi}$ error of system pressure which is of the same order of magnitude as the partial pressure of the decomposition products. A $0.1 F$ oscillation in the temperature control would mask a 0.29 psi pressure oscillation.

The instrumentation used in the test is shown in block diag ram in Figure 8. Photographs of the pile face instrumentation are shown in Figures 6 and 9. 
a. Measurement of Liquid and Vapor Phase Temperatures in the Autoclave

Platinum resistance thermometers were used as the primary ciement in the measurement of the temperature of the liquid and vapor phases. The vapor phase element was also used for the femperature control of the autoclave, Figure 10. The two resistance thermometers used in this test were made from 0.004 in, diameter piatinum wire bilifar wound on a threaded mandrel of lavite. The mandrel was inserted into a quartz tube $0.065 \mathrm{in}$. 1.D. and $1 / 8 \mathrm{in}, 0 . D$. The leads from the $0.004 \mathrm{in}$. platinum wire were attached to short lengths of $0.010 \mathrm{in}$. platinurs wire welded to 0.010 in. gold wire, which, in turn was welded to copper lead wire at the end of the quartz sheath. A compensating copper lead was welded at one of the platinum-gold junctions.

The Siemens three-lead method of measuring the resistance of the thernometers was used. A Leeds and Northrup precision Wheatstone bridge with a sensitive Rubicon enclosed light beam galvanometer was used in measuring the resistance of the thermometer, Figure 8 . It was possible to determine the resistance of the platinum thermometer to a precision of plus or rninus 0.002 ohms $(0.07$ ohms $=1$ degree F).

The resistance thermometers were calibrated at the ice and steam points before the test: it was planned to recover and recalibrate them at the ice, steam and sulfur points after the test. However, both were damaged upon removal at the conclusion of the tests and prevented postcalibration. As a result, the resistance thermometer calibrations used in these tests may be in error by a small but indeterminate amount.

\section{b. Automatic Temperature Control of Water in the Autoclave}

The unbalance in a bridge circuit, caused by a change in resistance of the vapor phase resistance thermometer, generated the signal for the autoclave temperature control system. The resistance of the vapor phase thermometer was used as the settion of the bridge opposite a preset variable resistor which fixed the thermometer resistance at which the bridge was balanced. The control signal was then amplified, converted to direct current and directed through the control windings of a saturable reactor regulating its impedance and thereby regulating the power supplied to the immersion heater in the autoclaves. Figure 10 illustrates a simplified circuit for the control of the autoclave temperature. This iype of control proved quite stable except for a slight shift over a long period of time which was attributed to ambient temperature effects on the components of the control bridge and to power line voltage fluctuations. However, temperature did not drift more than $0.2 \mathrm{~F}$ per hour, and not more than one degree $\mathrm{F}$ for any run. 


\section{c. Measurement of System Pressure}

Two methods, both employing a Bourdon tube primary element, were used to measure the pressure. A Crosby 12 in. test gage was used as a pressure indicator and a Bourdon tube connected to a Bailey electric pilot pick-up, Figuze 11, was used to record the pressure on a modified Brown recorder. Both elements were connected to the liquid phase header at the pile face. Two Crosby gages were used to measure the system pressure; a 12 in. test gage, -15 to $300 \mathrm{psi}$, was used in the lower temperature runs and a 12 in, test gage, 0 to $600 \mathrm{psi}$, was used for temperatures over $400 \mathrm{~F}$. The -15 to $300 \mathrm{psi}$ gage was graduated in $1 \mathrm{psi}$ divisions and was readable to $0.1 \mathrm{psi}$. Calibration with a dead-weight tester after the test showed the gage to be in error by as much as $3 \mathrm{psi}$ over the entire range scale. Similar calibration of the 0 to $600 \mathrm{psi}$ gage also gave a 3 psi error over the scale range.

A Bailey electronic telemeter pressure recorder was used to record system pressure. The movable core of a Bailey telemeter coil, variable inductance transformer, was attached to the tip of a berylliumcopper Bourd on tube; variations in coil inductance were transmitted to a modified Brown self-balancing bridge recording unit shown schematically in Figure 11. A series of 10 expanded scales, in addition to the full scale range, were used with the recorder. Use of the expanded scales gave an effective chart width of 100 inches, each expanded scale being about $150 \mathrm{psi}$. During calibration at Argonne and Oak Ridge, the system was quite stable and the pressure recorded had a reproducibility of plus or minus 1 psi. In use, the recorder had a tendency to drift in a random fashion such as might be expected in a circuit sensitive to ambient temperatuse variations. The drift was sufficient to mask the small system pressure changes due to recombination or decomposition. Therefore, only those pressure changes obtained from the Crosby test gages were used in the interpretations of the effects of temperature and pile flux on the irradiation of water.

\section{d. Measurement of the Temperature in Converter and Coolant Streams}

A set of six 30 gage iron constantan thermocouples was used in the apparatus. Only one of the se was positioned inside the autoclave liquid phase, the others being placed at various points in the flux converter for temperature monitoring. The se thermocouples were connected to a Leeds and Northrup Speedomax multipoint recorder and to a Brown millivolt indicator. Thermocouple locations were:

One in the thermocouple well in the autoclave liquid phase. 
Two on the coolant inlet and outlet lines at.juncture with the converter.

Two in side holes drilled into the aluminum of the converter.

One in a hole drilled in slug plug butting against a slug end.

System temperatures were determined by the more sensitive Brown millivolt indicator.

A high temperature alarm control, attached to the Brown millivolt indicator, was set for a maximum flux converter temperature of $300 \mathrm{~F}$.

\section{STEADY STATE RESULTS}

An important phase of this test was to obtain more data on the steady state levels of water decomposition and recombination at temperatures of $200-450 \mathrm{~F}$. An analysis of the design of the apparatus and instrumentation shows several systemic errors which limited the degree to which these small pressure risescould bedetected. The operating temperature of the water in the autoclave was measured with the resistance thermometer described in II-B-4-a. As was pointed out in that section, this thermometer cannot be relied upon to measure absolute temperatures due to possible calibration errors. It was, however, very precise in measuring snall temperature variations (plus or minus $0.1 \mathrm{~F}$ ).

Another factor leading to error in absolute temperature measurement of the system was the temperature gradient through the water in the autoclave resulting from the use of an immersion heater. As the heater and measuring resistance thermometer were in the liquid phase and the control resistance thermometer was in the vapor phase, the geometry of the heat flow probably resulted in a superheated liquid phase which, when measured and converted to equilibrium pressure, contributed to the negative values reported for the $\Delta P$ comparis on of system pressure with the steam tables. In the lower temperature ranges of 200-300F, this error would be small, but is significant in the higher temperature range. The temperature gradient could be kept quite low, for temperatures up to $300 \mathrm{~F}$, by proper control of the converter temperature so that there was only a 10-20 watt heat loss from the autoclave. However, the flux converter temperature could not exceed $300 \mathrm{~F}$, and consequently greater heat losses had to be accepted for the higher operating temperatures. The resulting heat loss amounted to as much as 150 watts in the 400-500F operation.range. 
For the se reasoris, the difference $(\Delta P)$ between the system pressure and the steam table pressure corresponding to system temperature, is not a true value for the decomposition products partial pressure. Therefore, while the subsequent data is reported in terms of $\triangle P$ where the system temperature is taken as that measured by the liquid phase resistance thermometer, these values are relative and only the $\Delta P$ values for a narrow temperature band can be directly compared.

This situation then dictated a comparison between pile off and pile on measurement of the gaseous decomposition product p.essures.

\section{A. Cunstant Temperature Steady State Results}

The constant temperature steady state runs were made by establishing a thermal steady state within the autoclave while the pile was shut down; maintaining the same temperature, the pressure change with the pile in operation was determined for the system with a liquid to vapor phase volume ratio of about $4: 1$. Four equilibrium runs at 235 to $250 \mathrm{~F}$ were made since this was in the range of greatest precision of measurement and better control could be obtained. Table II summarizes the pressure rises noted.

\section{TABLE II - EFFECT OF PILE FLUX ON DISSOCIATION PRESSURE AT CONSTANT TEMPERATURE}

\begin{tabular}{|c|c|c|}
\hline Fill & Temperature $F$ & Pressure Rise, psi \\
\hline 3 & 232 & +0.6 \\
4 & 255 & +0.4 \\
5 & 235 & +0.4 \\
6 & 238 & +0.6 \\
\hline
\end{tabular}

The water, double-demineralized and with an electrical resistivity of 2 to $4 \times 10^{6} \mathrm{ohm} \mathrm{cm}$., was subjected to a fast neutron flux of about $2 \times 10^{11}$

\section{B. Variable Temperature Steady State Results}

Two variable temperature steady state runs were made by first determining the reference steady state pressures of a water sample at 205, 304 and $405 \mathrm{~F}$ with the pile shut down; then with the pile in operation and duplicating the above temperatures, the autoclave pressures were 
determined. In these runs, variations in heat loss from the autoclave were unavoidable for each set of data because of the difficulty in compensating for the on-pile gamma and fission heating of the flux converter and autoclave. With the pile in operation, the flux converter temperature was regulated to correspond to the initial off-pile temperature, i.e., corresponding to 205,304 , and $405 \mathrm{~F}$ autoclave water temperature. With the pile in operation a large coolant flow was necessary to maintain the flux converter temperature predetermined by the off-pile experimental condition.

The results of these two runs are tabulated in $T$ able $I I I$ as difference between the off-pile and the on-pile system pressures, or $\Delta P^{\prime}=\Delta P$ (Pileon) - $\Delta P$ (Pile-off). Wattage differences or autoclave heat losses between off-pile and on-pile operation are also listed to show the experimental approximation achieved in balancing heat flow through the autoclaves.

TABLE III - EFFECT OF PILE FLUX ON DISSOCLATION PRESSURES FOR SEVERAL TEMPERATURES

\begin{tabular}{|c|c|c|c|c|}
\hline \multirow{2}{*}{ Temp. F. Fill 10 } & \multicolumn{2}{c|}{ Fill 13 } \\
\cline { 2 - 5 } & $\begin{array}{c}\Delta \mathrm{P}^{\prime} \\
\mathrm{psi},\end{array}$ & $\begin{array}{c}\text { Wattage Differential } \\
\text { On-Pile and Off-Pile } \\
- \text { Watts- }\end{array}$ & $\begin{array}{c}\Delta \mathrm{P}^{\prime} \\
\mathrm{psi}\end{array}$ & $\begin{array}{c}\text { Wattage Differential } \\
\text { On-Pile and Off-Pile } \\
- \text { Watts- }\end{array}$ \\
\hline 205 & +2.2 & -25 & +0.4 & -9 \\
305 & +1.5 & -20 & -1.0 & -4 \\
405 & -0.5 & -35 & -5.4 & -1 \\
\hline
\end{tabular}

From Table III it is seen that several $\Delta \mathrm{P}^{\prime}$ values are negative showing an apparent lower pressure with the pile in operation. The probable explanation for the negative values of $\Delta P^{\prime}$ may be found in the gamma heating of the platinum and lavite core of the resistance thermometer. For the on-pile values, the apparent temperature as measured and controlled by the resistance thermometer would be higher than the actual temperature of the water. A comparison with the equivalent pressure for the resistance thermometer temperature would result in lower and in some cases negative $\angle P^{\prime}$ values.

\section{Discussion}

The constant temperature steady state results are more reliable than the variable temperature results, as all variables were held constant before and after pile start-up with the exception of the effect of gamma heating in the resistance thermometer. The effect of gamma heating was minimized at the lower temperature range of 230 to $255 \mathrm{~F}$ in the constant 
temperature runs because the saturation steam table corrections are low, amounting to approximately 0.4 psi per degree $F$ ahrenheit.

There is also a difference in the literature values of steam saturation temperature and pressure in the higher temperature regions. The pressures from this test were compared with the values presented by Keenan and Keyes. Variations in values are reported by several observers. (3) The variation in the reported vapor pressure for water at different temperatures is shown in Table IV.

TABLE IV - VARIATION IN PUBLISHED VAPOR PRESSURE DATA FOR WATER(3)

\begin{tabular}{|c|c|c|}
\hline \multicolumn{2}{|c|}{ Temperatures } & $\begin{array}{c}\text { Maximum Difference } \\
\text { psi }\end{array}$ \\
\hline C & $F$ & 0 \\
100 & 212 & 0.12 \\
150 & 302 & 3.8 \\
200 & 392 & 9.5 \\
260 & 500 & \\
\hline
\end{tabular}

The variable temperature steady state values contain too many operational variables for a detailed analysis. 


\section{RECOMBINATION RESULTS}

\section{A. Effect of Temperature on Recombination}

The decomposition product concentrations resulting from the irradiation of wate $r$ are determined by a steady-state balance between the rate of . decomposition of the water molecules and the rate of recombination. of the decomposition products. Hydrogen and oxygen gases were added to water under steady state conditions at various temperature and flux conditions as the most direct method of measuring the recombination rate. Figure 12 summarizes the recombination rate for four fills under a fast flux of approximately $2.0 \times 10^{11}$ at $202 \mathrm{~F}, 305 \mathrm{~F}, 404 \mathrm{~F}$ and $483 \mathrm{~F}$. These curves are a plot of the rate of change of the system pressure difference (system pressure minus steam saturation values) versus time after hydrogen and oxygen gas introduction. In all runs, oxygen gas was added first through the gas phase sampling line followed by a hydrogen gas introduction through the liquid phase sampling line. Temperatures were measured with the liquid phase resistance thermometer. (It is to be noted that the system temperature measurement in these series of experiments was subject to the same errors previously discussed.) From Figure 12 the initial rate of combination is shown in Table $\mathrm{V}$.

These combination rates are based on the linear sections of the curves between one and two hours after hydrogen introduction. Experimental dificiculties precluded a quantitative evaluation of the combination rates. While the gas additions to Fills 18,24 and 25 were approximately stoichiometric mixtures of hydrogen and oxygen gases for the formation of water, Fill 17 had a considerable excess of hydrogen. Fills 17 and 18 contained double-demineralized water while Fills 24 and 25 contained double-distiiled water. Data for Fill 17 has a discontinuity in its rate curve due to the $X-10$ 
TABLE V - RATE OF COMBINATION OF HYDROGEN AND OXYGEN AS A FUNCTION OF TEMPERATURE

\begin{tabular}{|c|c|c|c|c|}
\hline \multirow{2}{*}{ Fill } & \multirow{2}{*}{ Temp. F } & $\begin{array}{c}\text { Rate of Pressure Drop } \\
\text { psi/hr. }\end{array}$ & \multicolumn{2}{|c|}{$\begin{array}{c}\text { Volume Gases Added } \\
\text { (cc STP) }\end{array}$} \\
\cline { 4 - 5 } & 202 & 4.7 & $\mathrm{H}_{2}$ & $\mathrm{O}_{2}$ \\
\hline 18 & 305 & 5.6 & 70.5 & 36.4 \\
24 & 404 & 9.6 & 124.3 & 33.8 \\
25 & 483 & 22.2 & 77.3 & 36.3 \\
& & & 99.4 & 49.7 \\
\hline
\end{tabular}

pile operating at a considerably reduced power level for a short period of time. This reduced power period, however, was plotted on an equivalent time scale for $3550 \mathrm{kw}$ power level. With the exception of a slight lip in the curve at the time of power level change, the equivalent time scale resulted in an interpolated smooth curve as is shown by the dotted line of Figure 12. Similar plots are made in Figure 13 for three fills at a reduced flux $\left(1.1\right.$ to $\left.1.2 \times 10^{11}\right)$ and temperatures of $204 \mathrm{~F}, 304 \mathrm{~F}$, and $405 \mathrm{~F}$. As may be seen in these graphs, Fill 14, at 204F, has a steady rate of pressure decrease over the entire period of the graph, losing 19 psi in 10 hours. Fill $14-A$, at 304F, reached a leveling off period in less than 2 hours, losing $4.5 \mathrm{psi}$. Fill 15, at $405 \mathrm{~F}$, lost $17.8 \mathrm{psi}$ in 2 hours 15 minutes.

In these lower flux gaseous combination runs, the ratios of the added hydrogen to oxygen are lower than in the corresponding runs at full power flux. The hydrogen-oxygen addition ratio for Fills 14 and 14-A is only slightly greater than 1:1, giving an oxygen excess, and the ratio for Fill 15 is slightly greater than 2:1. This makes direct comparison of the reduced power combination rates with those of the full power operation uncertain. In the full-power runs, Fill 17, at 305F, was the only one that had a large deviation from an approximate $2: 1$ hydrogen oxygen ratio - the hydrogen to oxygen ratio for Fill 17 was about $4: 1$.

This set of comparison combination rate curves clearly shows an appreciable effect of temperature on the rate of chemical combination of hydrogen and oxygen when the gases are added to a steady state mixture of water and its decomposition products under pile radiation. These combination rates are a measure of the rate of the back reaction of the decomposition products of water and support the results of previous investigator $s(4,5)$ which show lower steady state decomposition product pressures for rising temperature. 
Several contributing factors made it impossible tc treat the combination reaction kinetically. First, there is no separation of experimental data into liquid and vapor phase combination rates of reaction as the re were no single phase runs made during the test. Secondly, as the gas was introduced into the vapor phase of the autoclave, the pressure drops plotted in Figures 14 and 15 include the rate of solution of the two gases. These rates of solution are believed to be small in comparison with the rate of combination.

\section{B. Recombination as a Function of Flux}

That pile flux directly promotes combination of hydrogen and oxygen gases is clearly shown in the graphs for Fills 17 and 18 of Figure 12 . The data for Fill 18, at 202F, Figure 14, shows that radiation is the motivating factor in the combination reaction. With the pile down, $36.4 \mathrm{cc}$ STP oxygen was added at reference point No. 1 and $70.5 \mathrm{cc}$ STP hydrogen was added at reference point No. 2. After both gases were added to the system, the pressure remained essentially contant, within plus or minus $2.5 \mathrm{psi}$, until the pile went up to $3500 \mathrm{kw}$ at reference point No. 3. Immediately following pile start up the pressure dropped smoothly until a new steady state was reached, In Fill 17, at 305F, Figure 15, the steady state level remained at an average $-4.5 \triangle P$ for 23 hours. Then $33.8 \mathrm{cc}$ STP oxygen gas and $124.3 \mathrm{cc}$ ST $P$ hydrogen gas were added at a system temperature of $204 \mathrm{~F}$ (to reduce system pressure for the introduction). The temperature was then brought back to $305 F$ and readings resumed.

The apparatus, in an epithermal flux of $2.0 \times 10^{11}$, was operating during the gas addition and for a period of 27 minutes after gas addition. The pile was shut down, and then started coming up to a flux level of $1.1 \times 10^{11}$. At the same time, the first reading was taken after reaching a steady state at $305 \mathrm{~F}$. In three minutes the flux level dropped to $9 \times 10^{90}$ and was held there for 35 minutes. During this time the pressure dropped 1.6 psi, appearing to level out at $\Delta P=+19.6$. The flux was then raised to $2.0 \times 10^{11}$ for the remainder of the reaction. In the first hour after the power increase, the pressure dropped 5.5 psi corresponding to the 2.7 psi per hour at the $9 \times 10^{10}$ flux level. The apparent leveling out of the curve just before 0100 is possibly due to the effects of the increased flux on the temperature of the resistance thermometer and to a change in the cemperature gradients within the autoclave due to a difference in the radiation heating of the system components.

Experiments were conducted to obtain combination rate data at $200 \mathrm{~F}$, $300 \mathrm{~F}$ and $400 \mathrm{~F}$ summarized in Table VI, with the pile at normal operating power and with the pile at two-thirds power. Results are graphed in Figures 16 and 17; the ratio of hydrogen to oxygen gases introduced were too varied to yield combination rates which would be directly comparable. 
TABLE VI - OPERATIONAL VARIATIONS IN THE EFFECT OF FLUX DENSITY ON COMBINATION

\begin{tabular}{|c|c|c|c|c|c|}
\hline Temp. & Fill & $\begin{array}{c}\text { Epithermal } \\
\text { Flux }\end{array}$ & $\mathrm{O}_{2}$ & $\mathrm{H}_{2}$ & Ratio \\
\hline $204 \mathrm{~F}$ & 14 & $1.2 \times 10^{11}$ & 46.3 & 48.7 & $1: 1$ \\
202 & 18 & $2.1 \times 10^{11}$ & 36.4 & 70.5 & $2: 1$ \\
304 & $14 \mathrm{~A}$ & $1.2 \times 10^{11}$ & 62.1 & 89.6 & $12: 1$ \\
305 & 17 & $2.0 \times 10^{11}$ & 33.8 & 124.3 & $4: 1$ \\
404 & 15 & $1.1 \times 10^{11}$ & 36.3 & 77.3 & $2: 1$ \\
405 & 24 & $1.9 \times 10^{11}$ & 42.8 & 86.4 & $2: 1$ \\
\hline
\end{tabular}

\section{FUTURE PROGRAM}

The design of the apparatus used in this experiment is being modified as a result of the experience gained in the operations at Oak Ridge. A similar test will be run in the Chalk River Reactor using improved equipment to explore many of the qualitative trends indicated in the results obtained in Oak Ridge.

\section{BIBLIOGRAPHY}

1. Allen, A. O. et al. "Decomposition of Water and Aqueous Solutions under Pile Irradiation" ORNL-130 October 11, 1949.

2. Fromm, L. W. "Decomposition of Water at High Temperatures and Pressures under Reactor Irradiation" ORNL-404 September 16, 1949.

3. Dorsey, N.E. "Properties of Ordinary Water Substance" Reinhold, 1940 p. 567.

4. Toulis, William J. "The Decomposition of Water by Radiation" University of California Radiation Laboratory, February 10, 1950.

5. Allen, A. O. MDDC-363 (1946).

6. Pray, H. A., Schweiskert, C. 5. ., Minnich, B. H. "The Solubility of Hydrogen, Oxygen, Nitrogen and Helium in Water at Elevated Temperatures" Battelle Memorial Institute, May 15, 1950. 


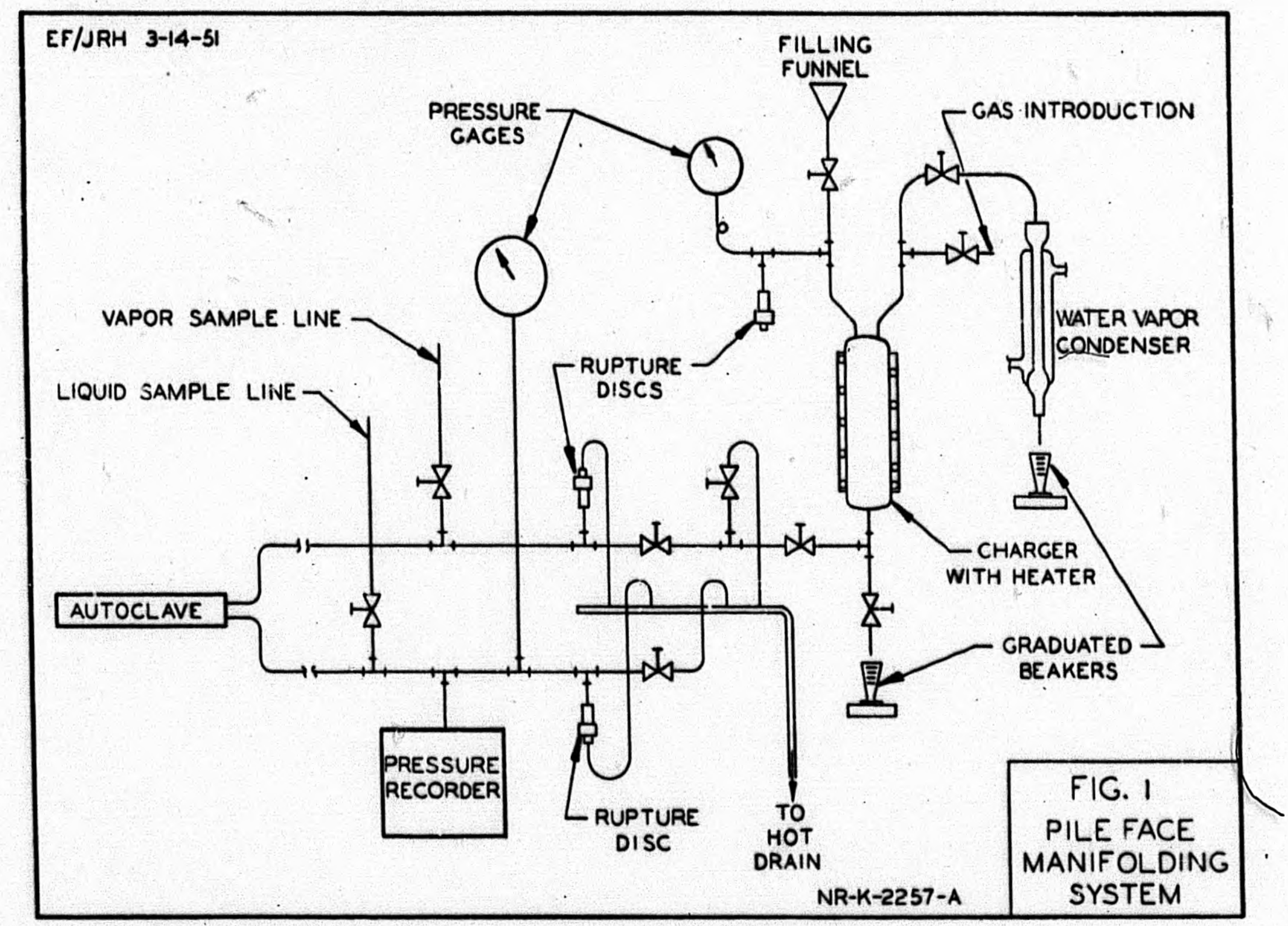




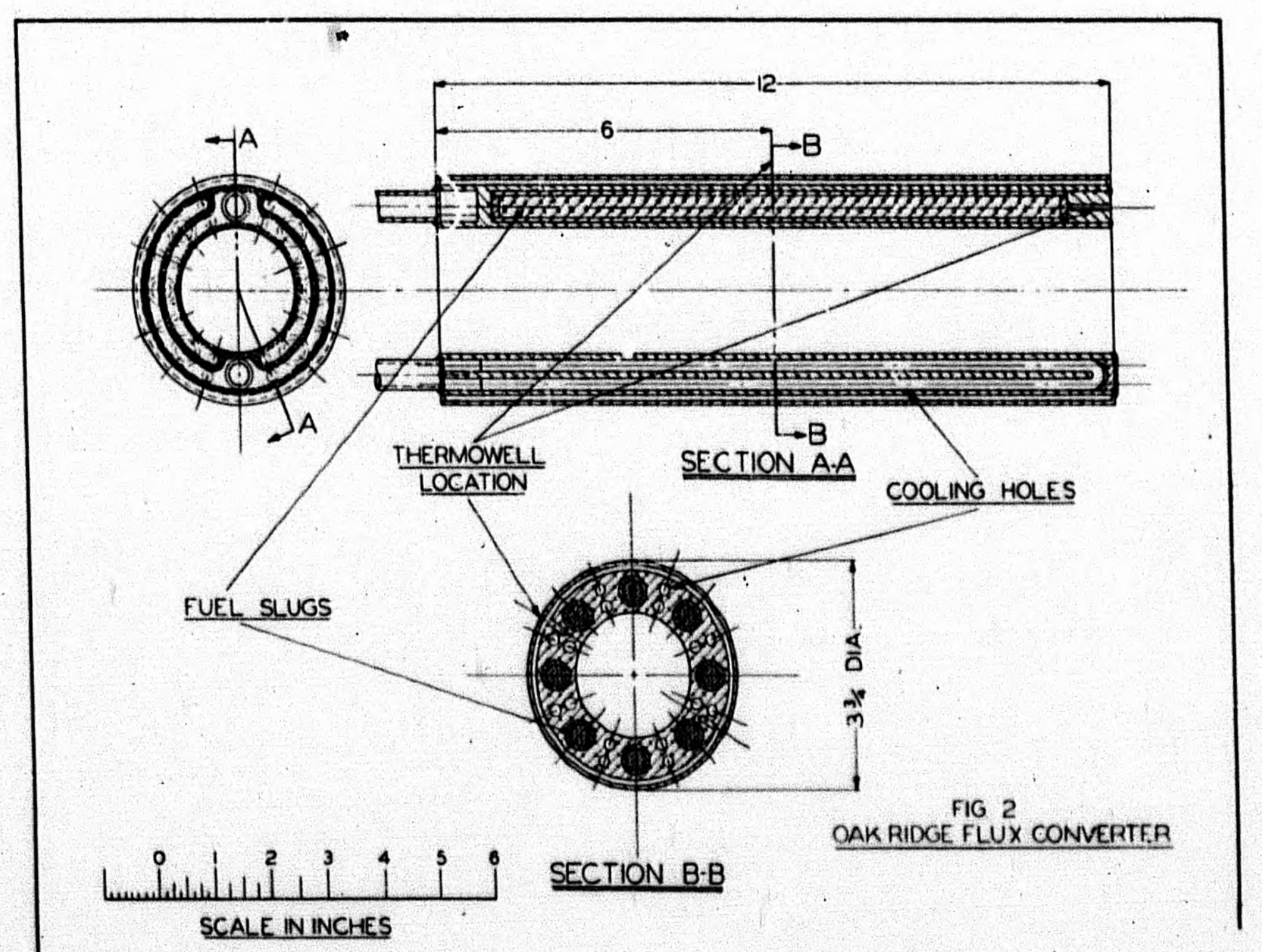




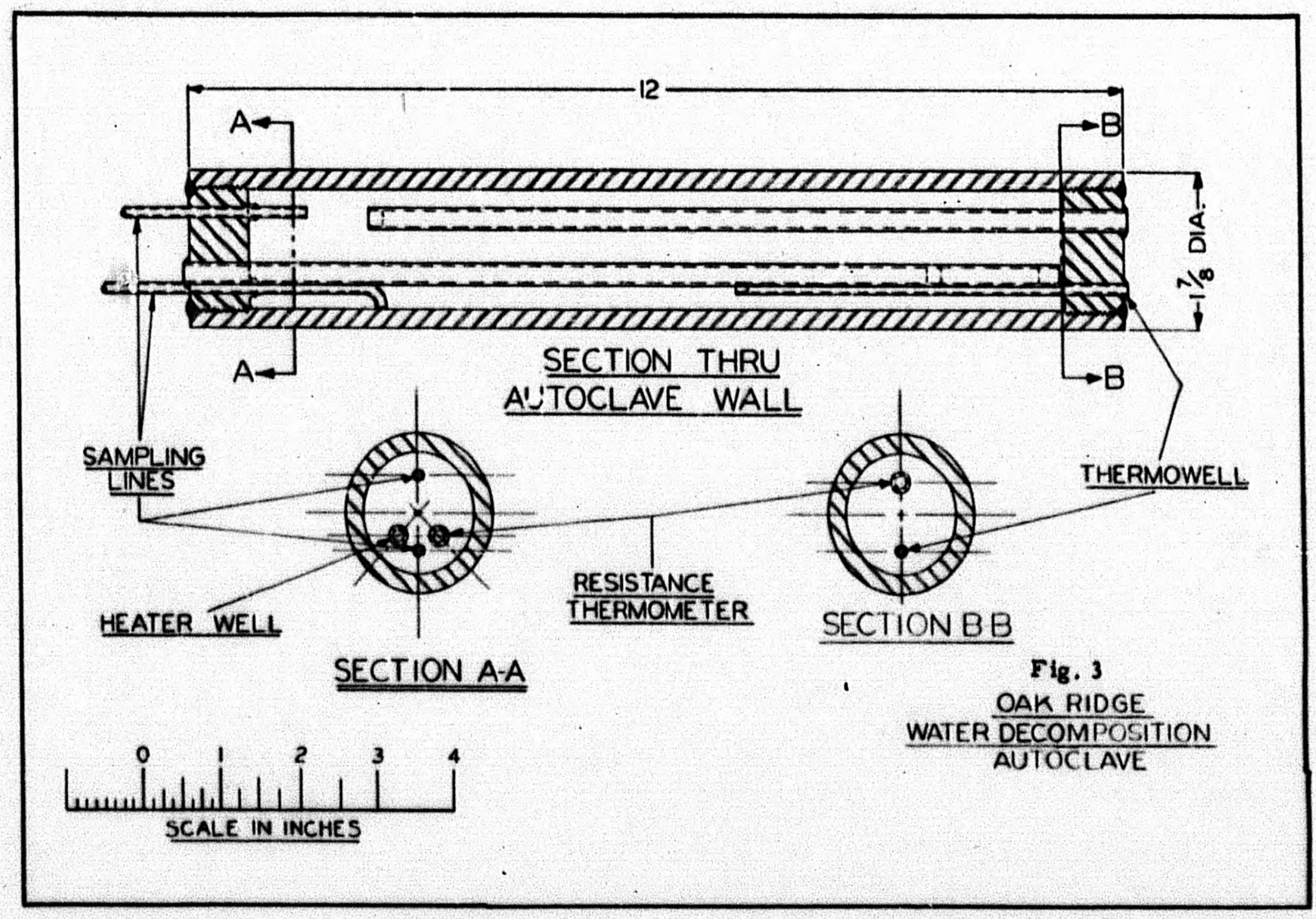


Fig. 4

AUTOCLAVE AND CONVERTER

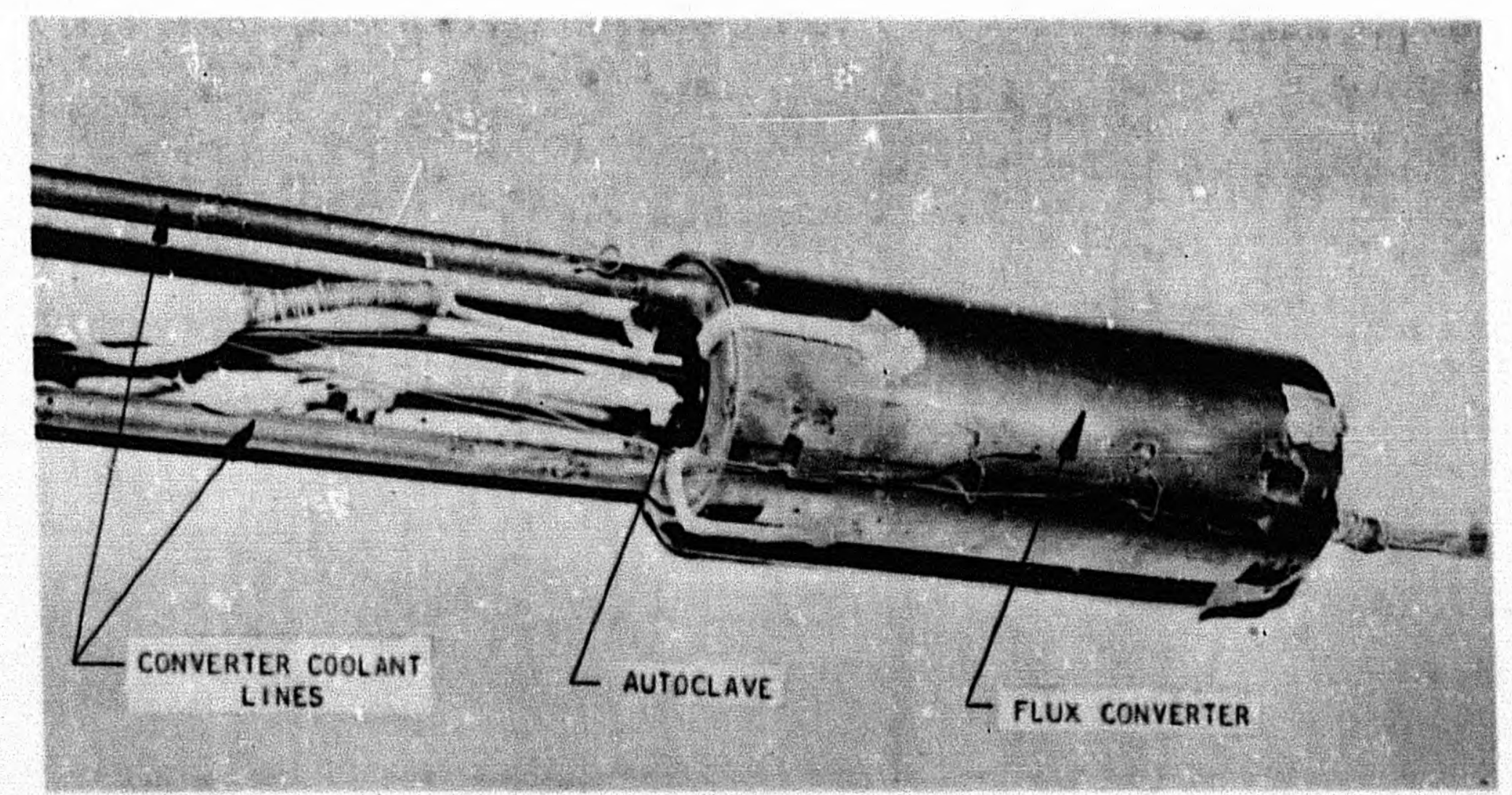


Fig. 5

AUTOCLAVE AND CONVERTER INSTRUMENTS

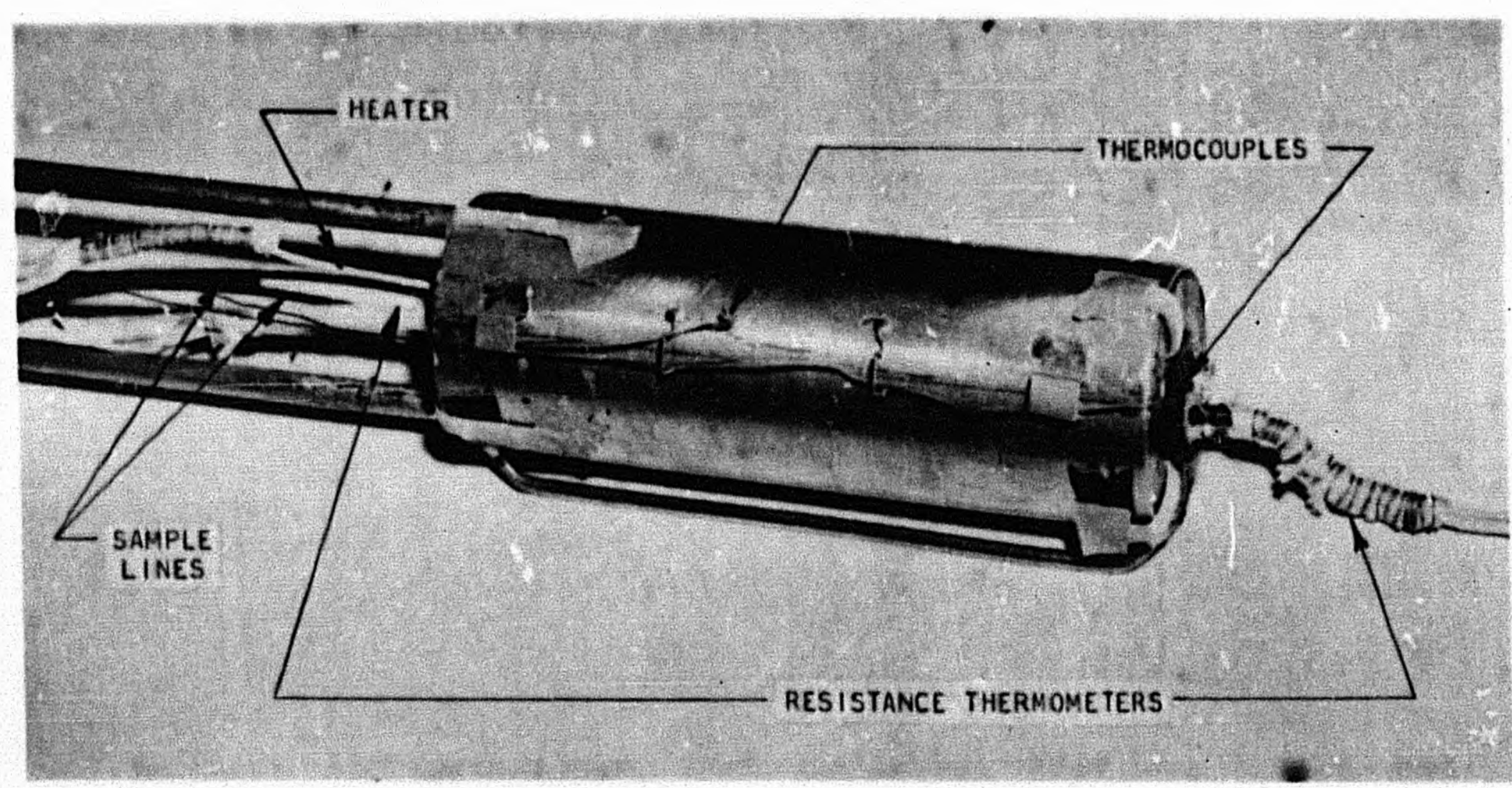




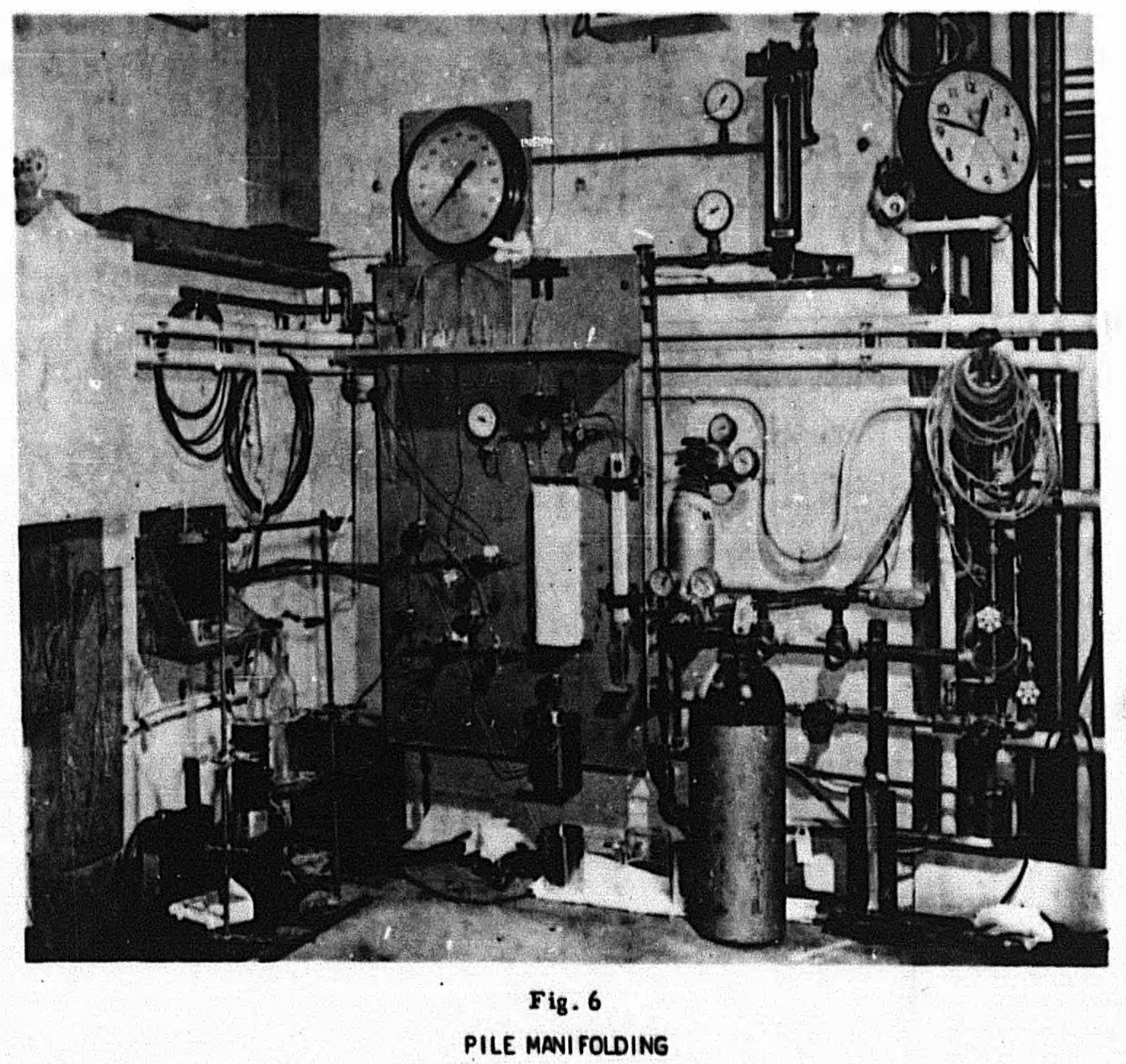




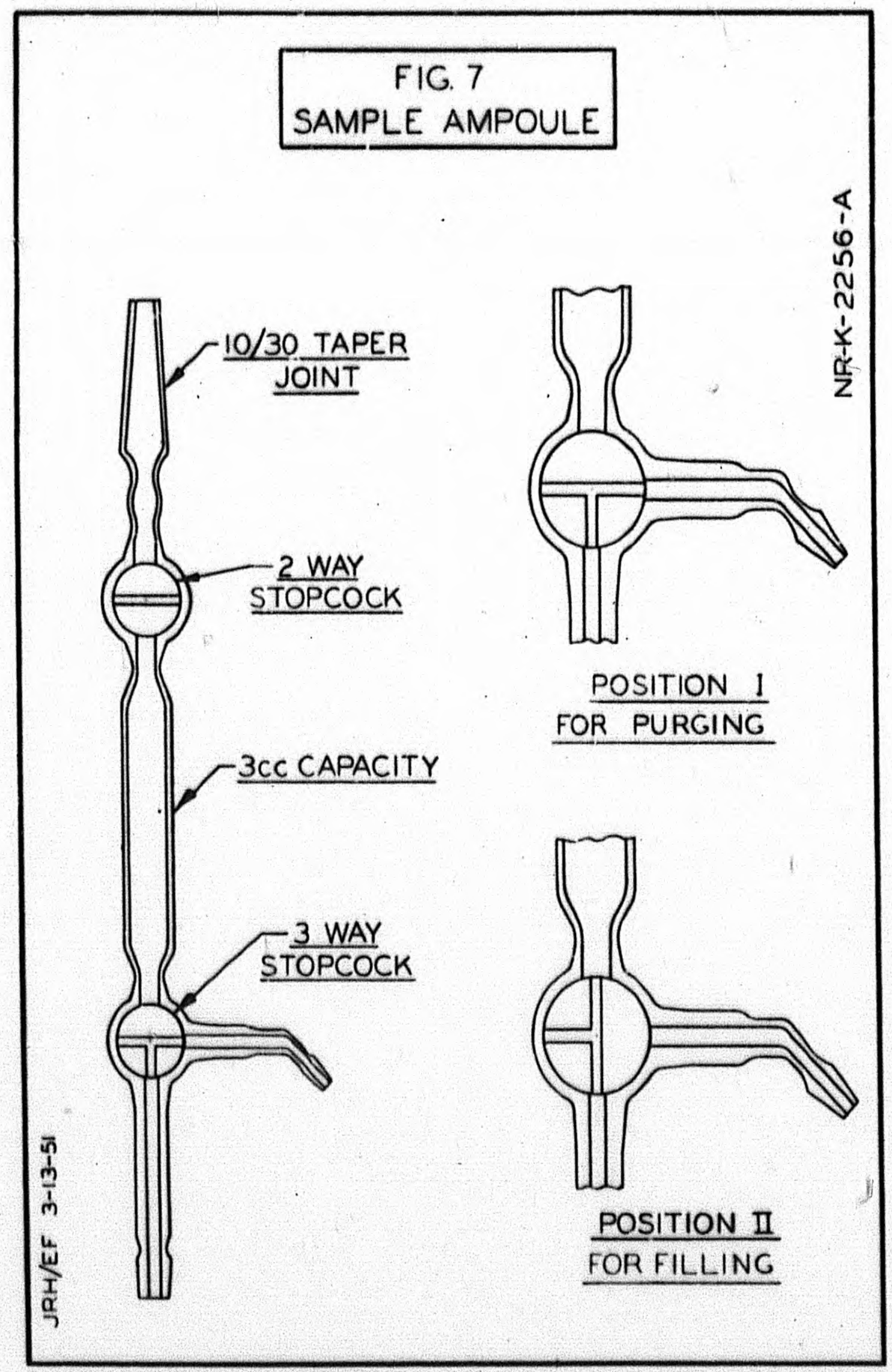




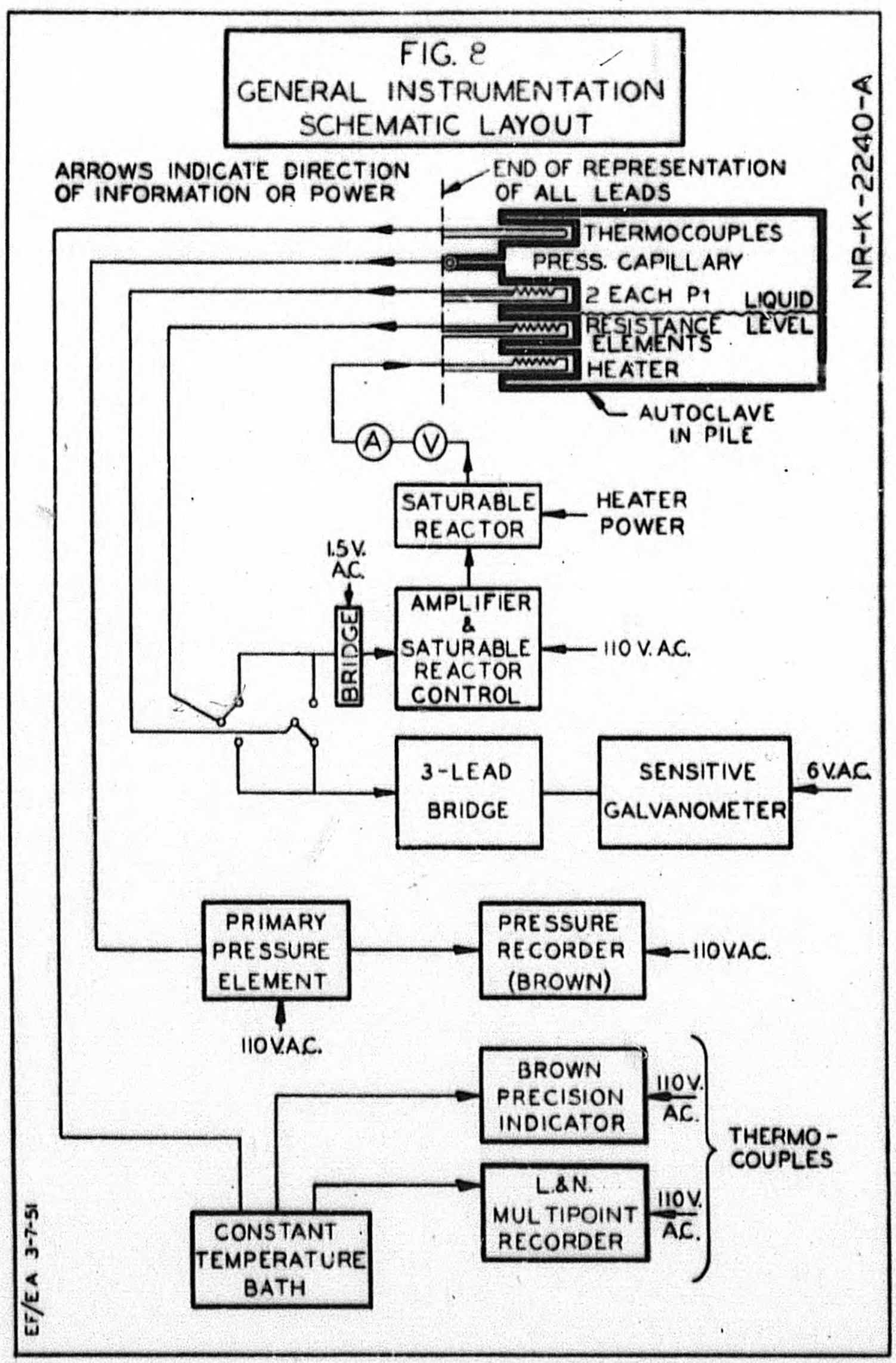


$51 x=9$

INSTRLMENT FANEL

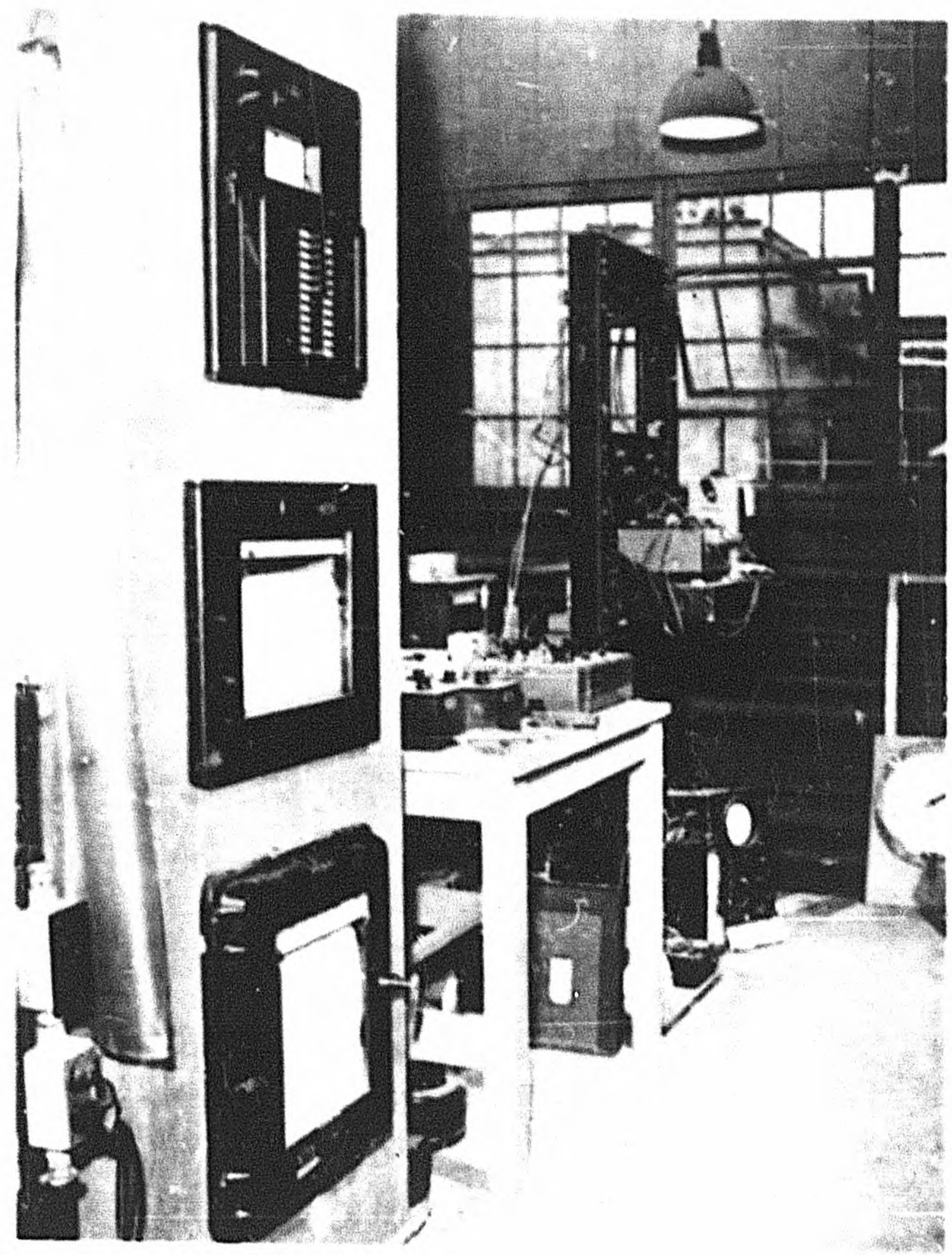




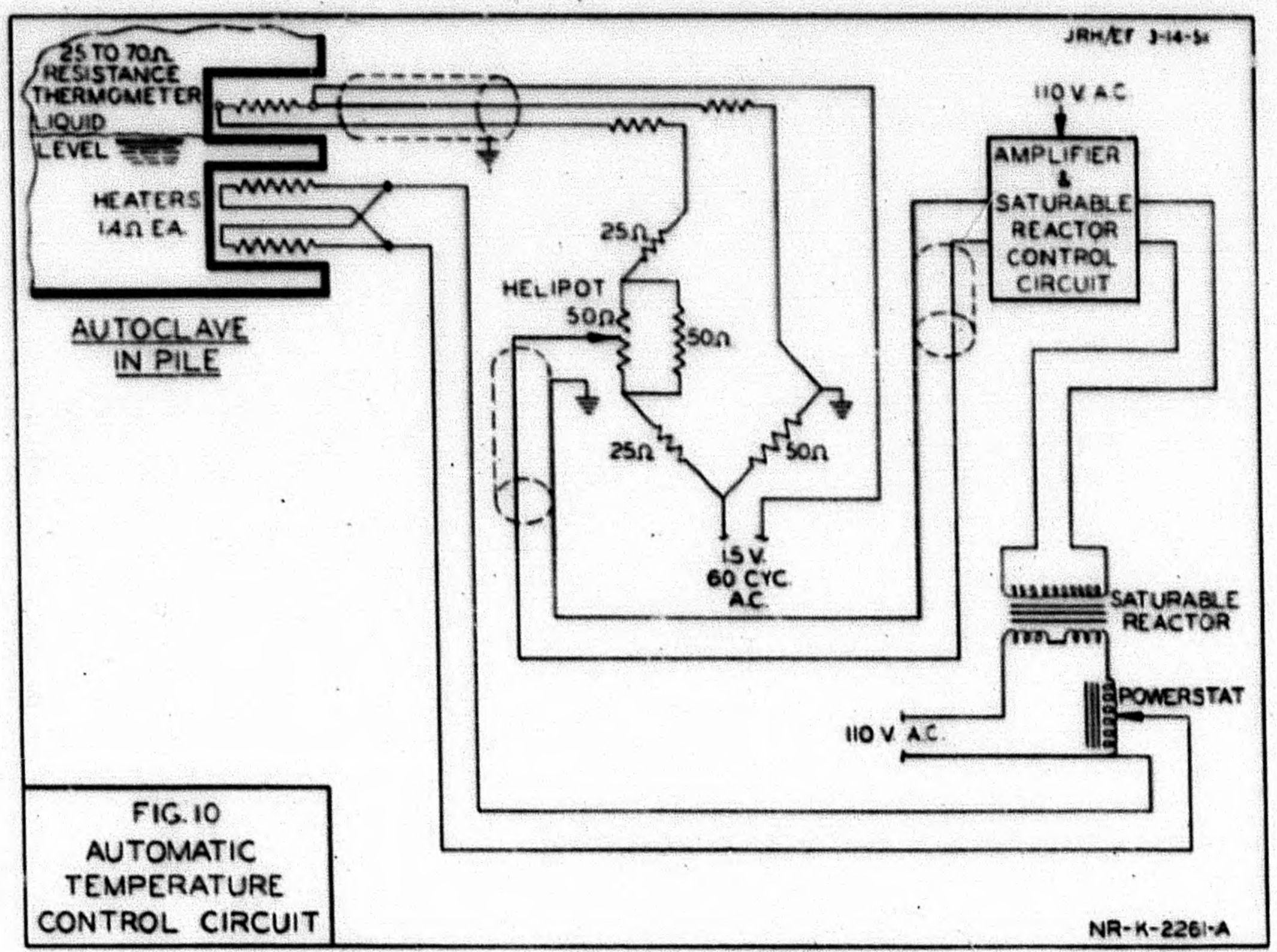




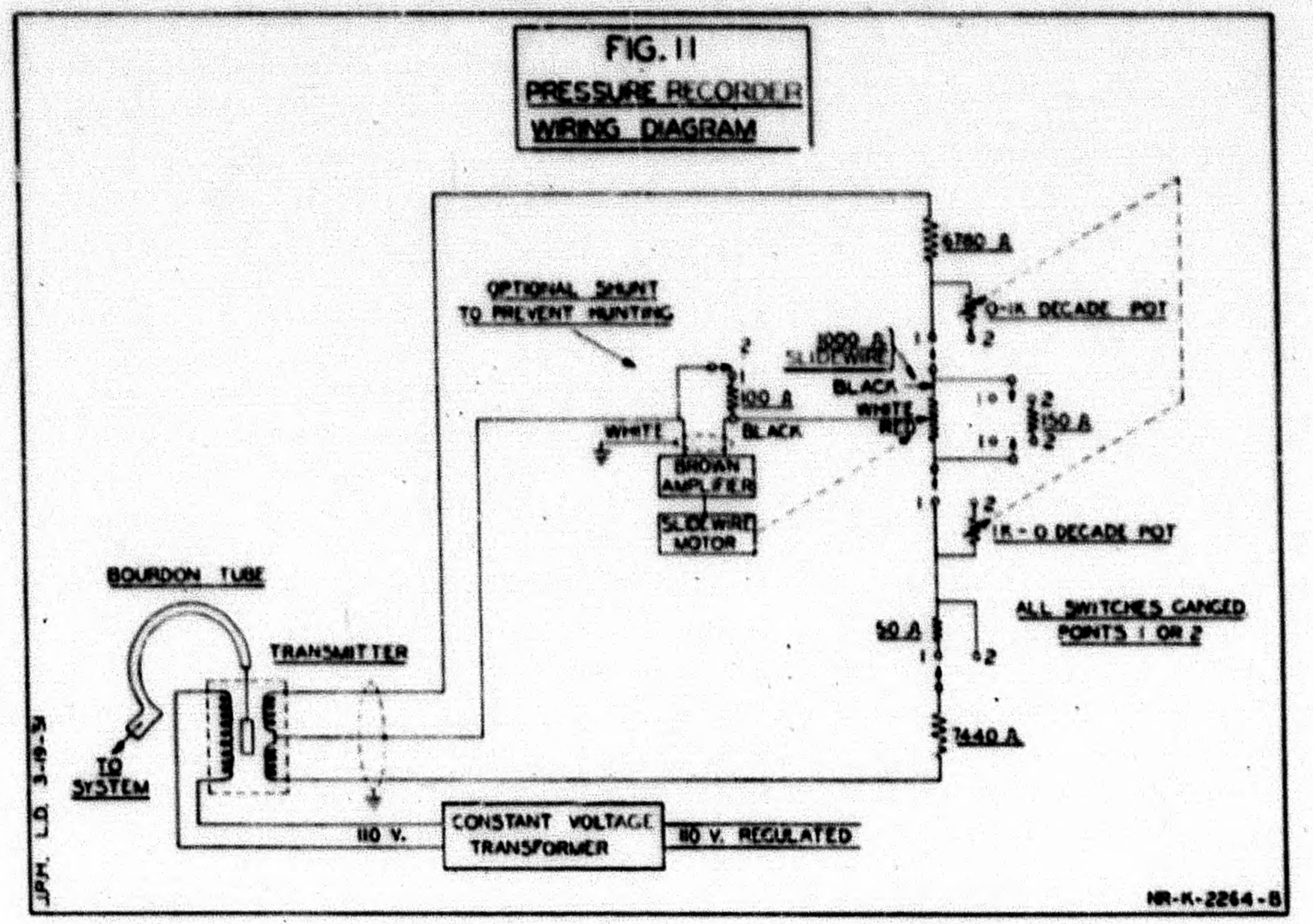




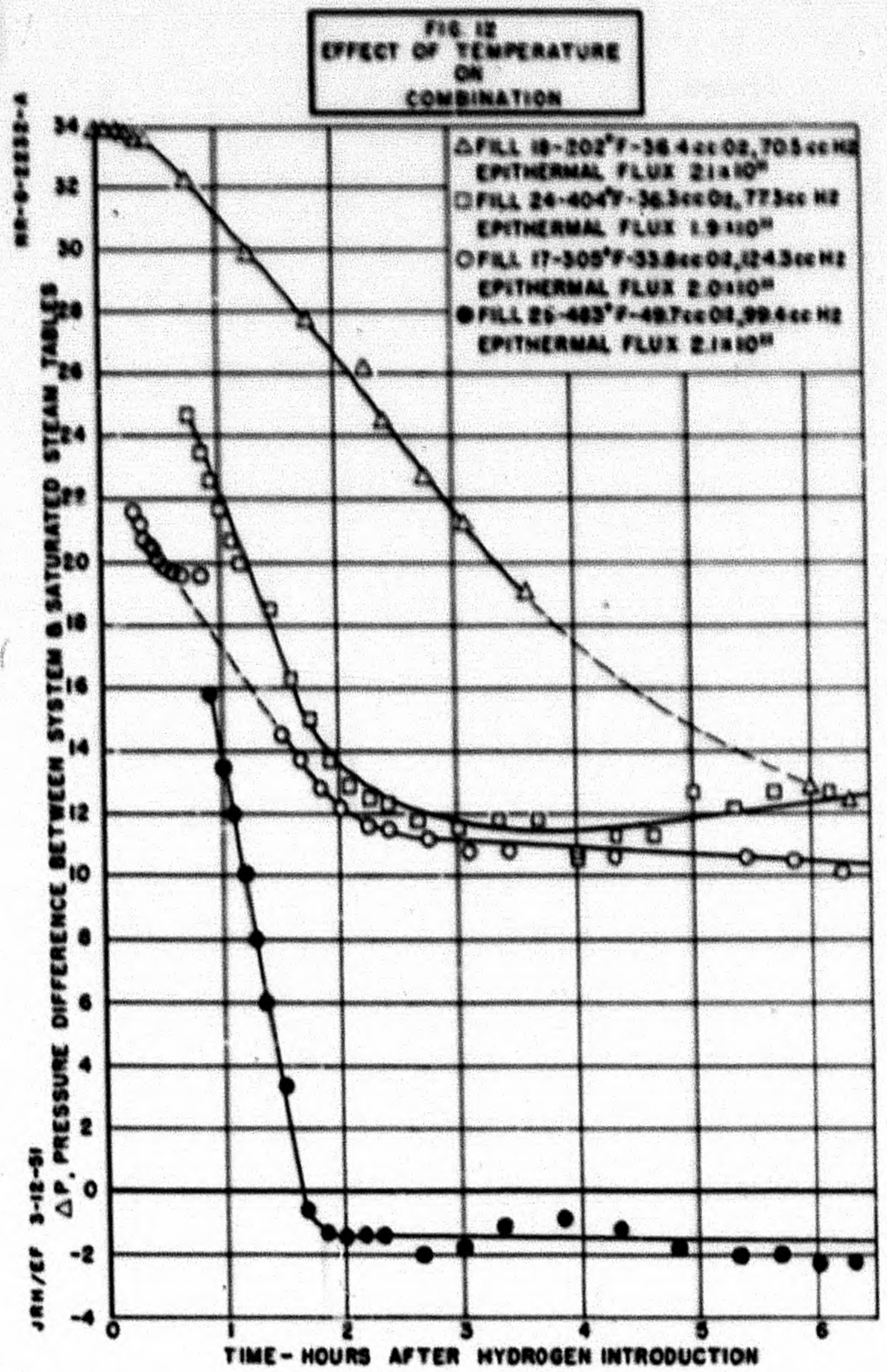




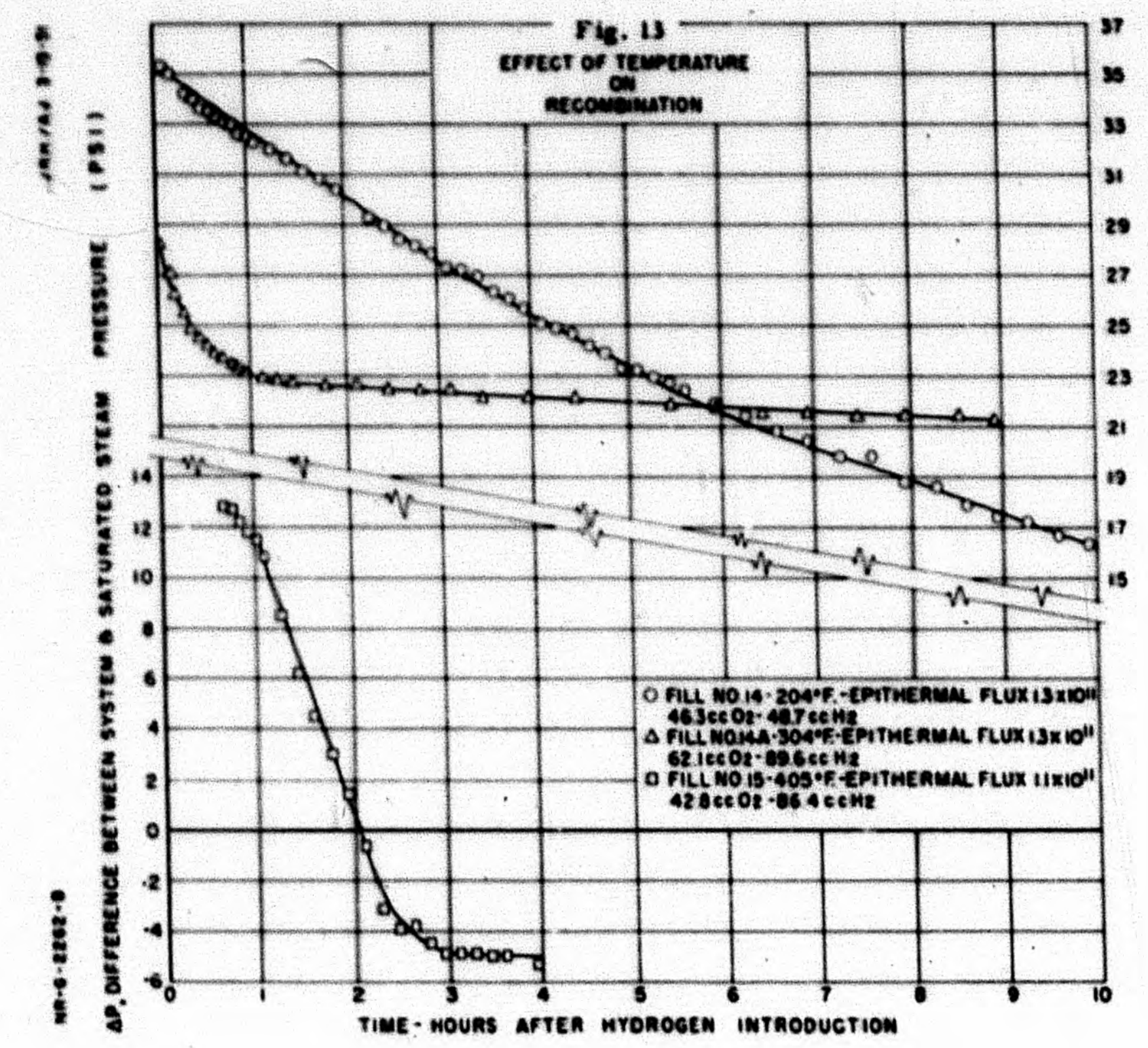




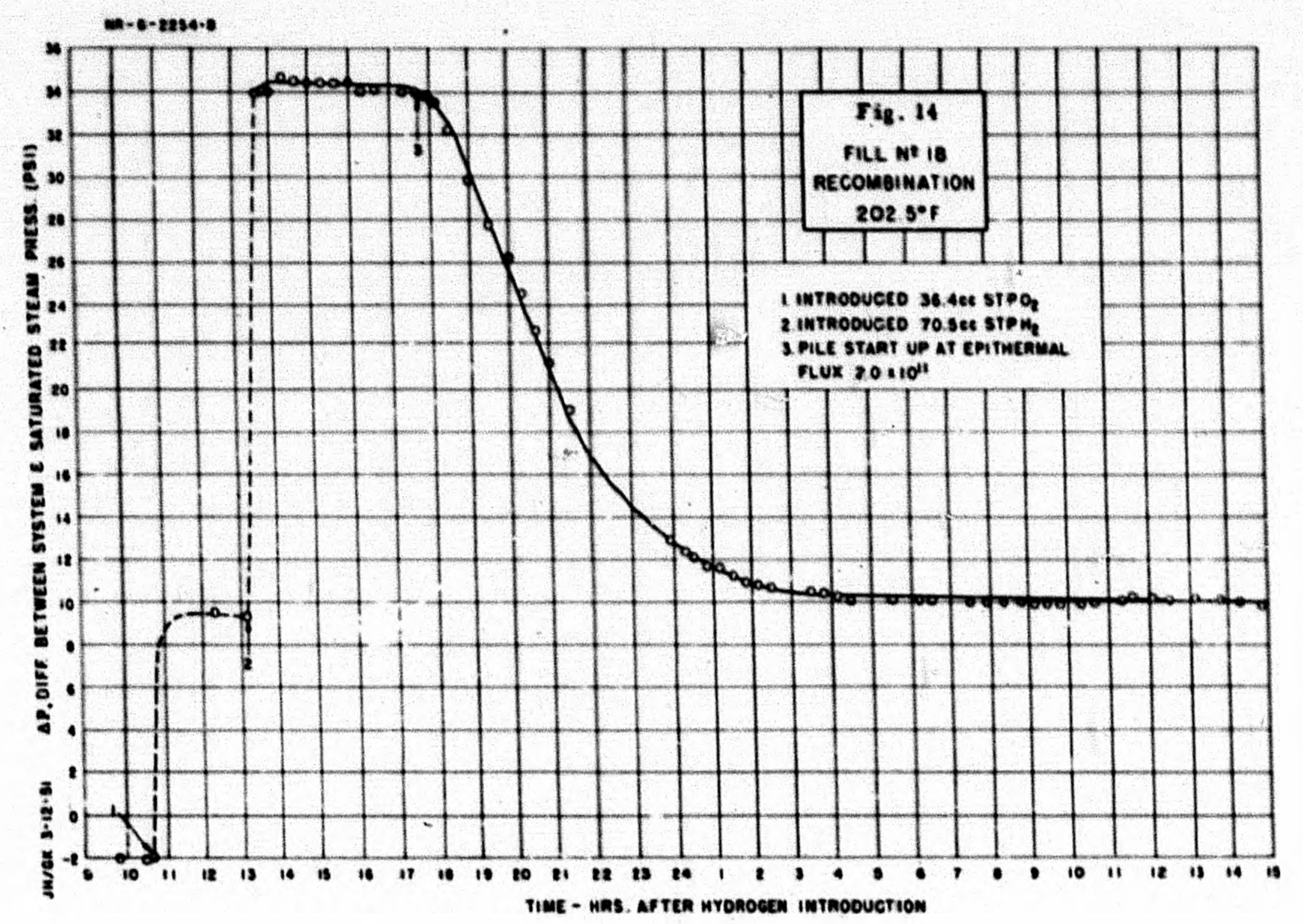




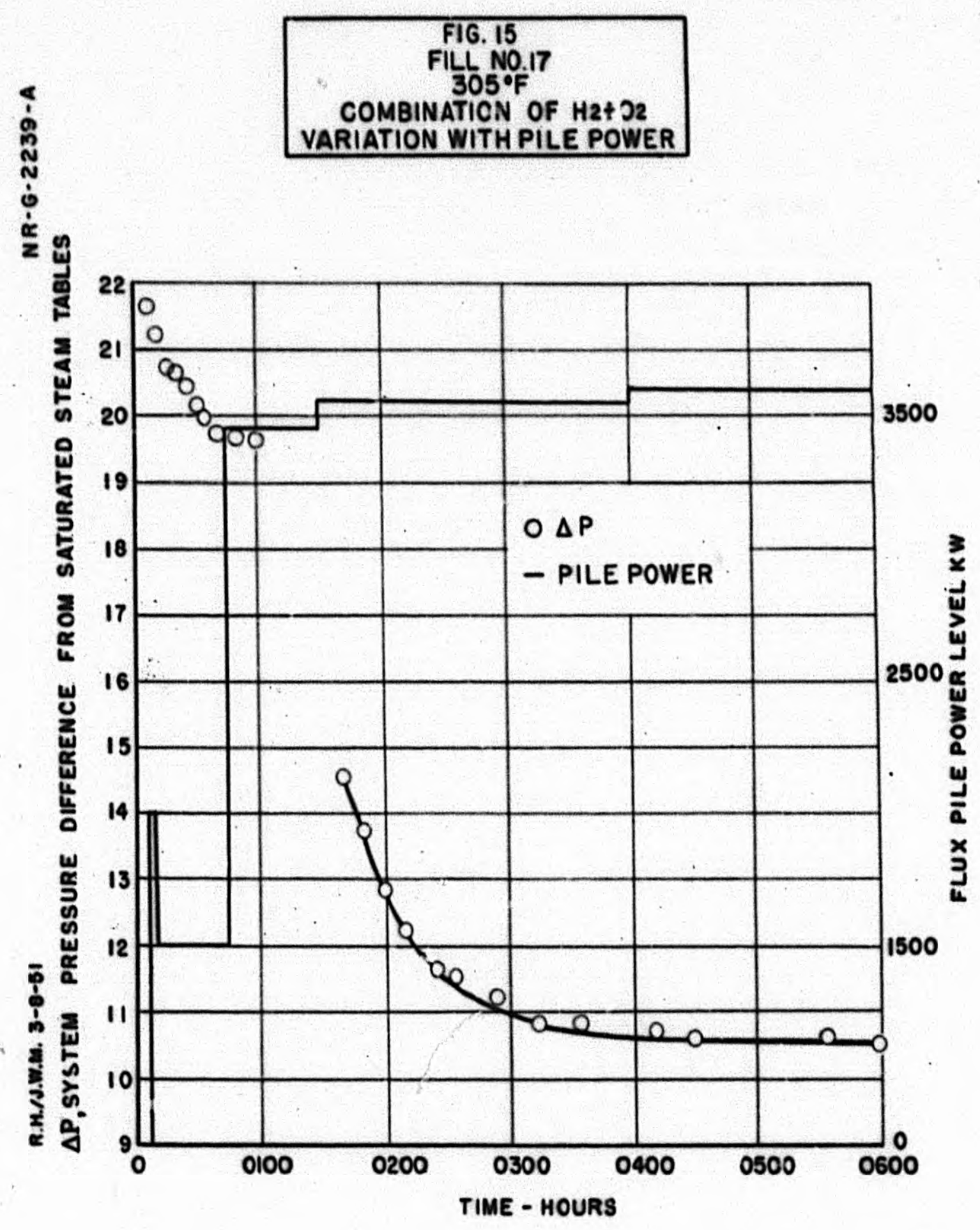




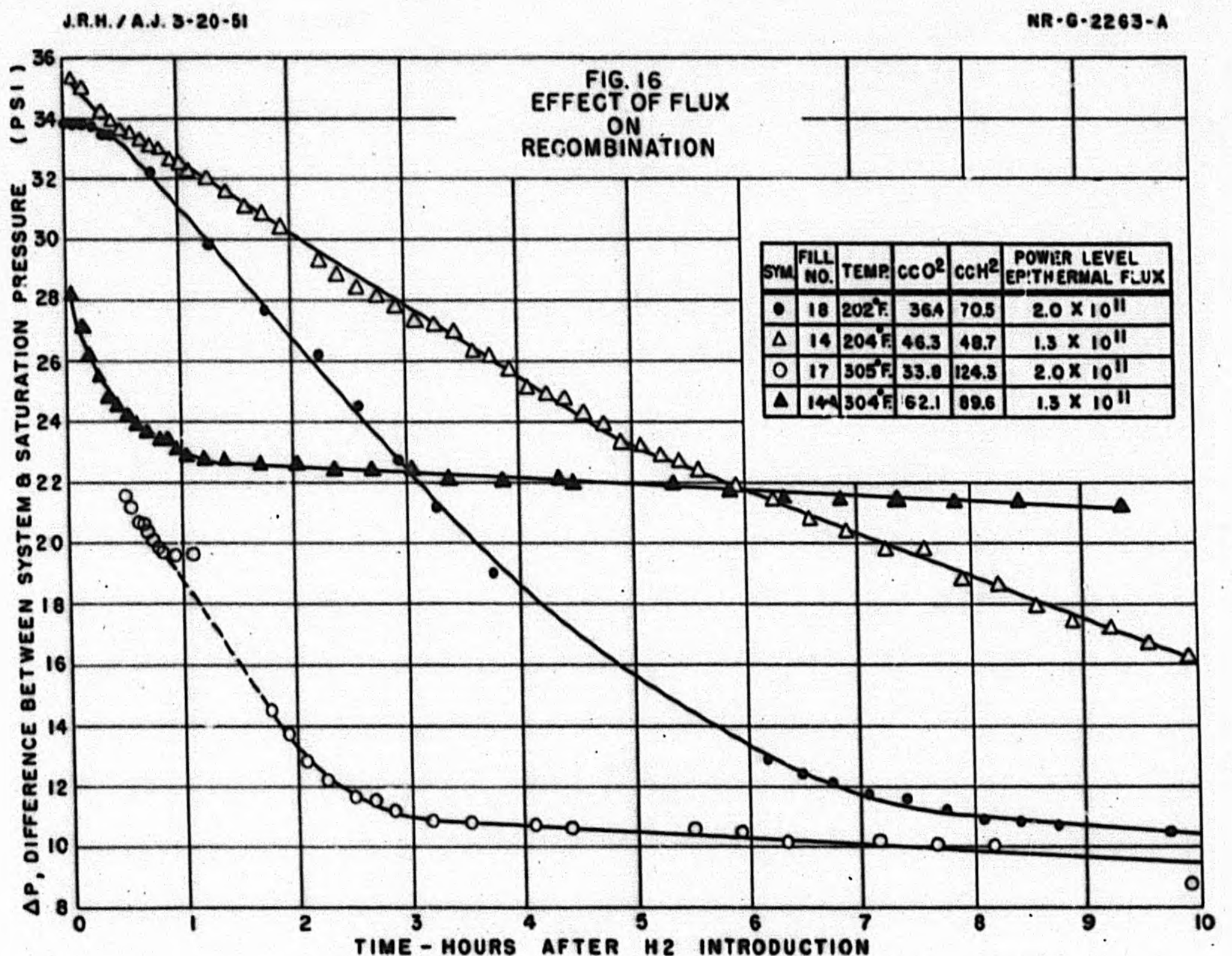




\begin{tabular}{|l|}
\hline Fig. 17 \\
EFFECT OF FLUX \\
ON \\
RECOMBINATION
\end{tabular}

O FILL $24-404^{\circ} \mathrm{F}-36.3 \mathrm{CCO}_{2}, 77.3 \mathrm{CCH}_{2}$-EPITHERMAL FLUX $2.0 \times 10^{\prime \prime}$

$\triangle$ FILL $15-405^{\circ} \mathrm{F}-42.8 \mathrm{ccO}_{2}, 86.4 \mathrm{CCH}_{2}$-EPITHERMAL FLUX $1.1 \times 10^{\prime \prime}$

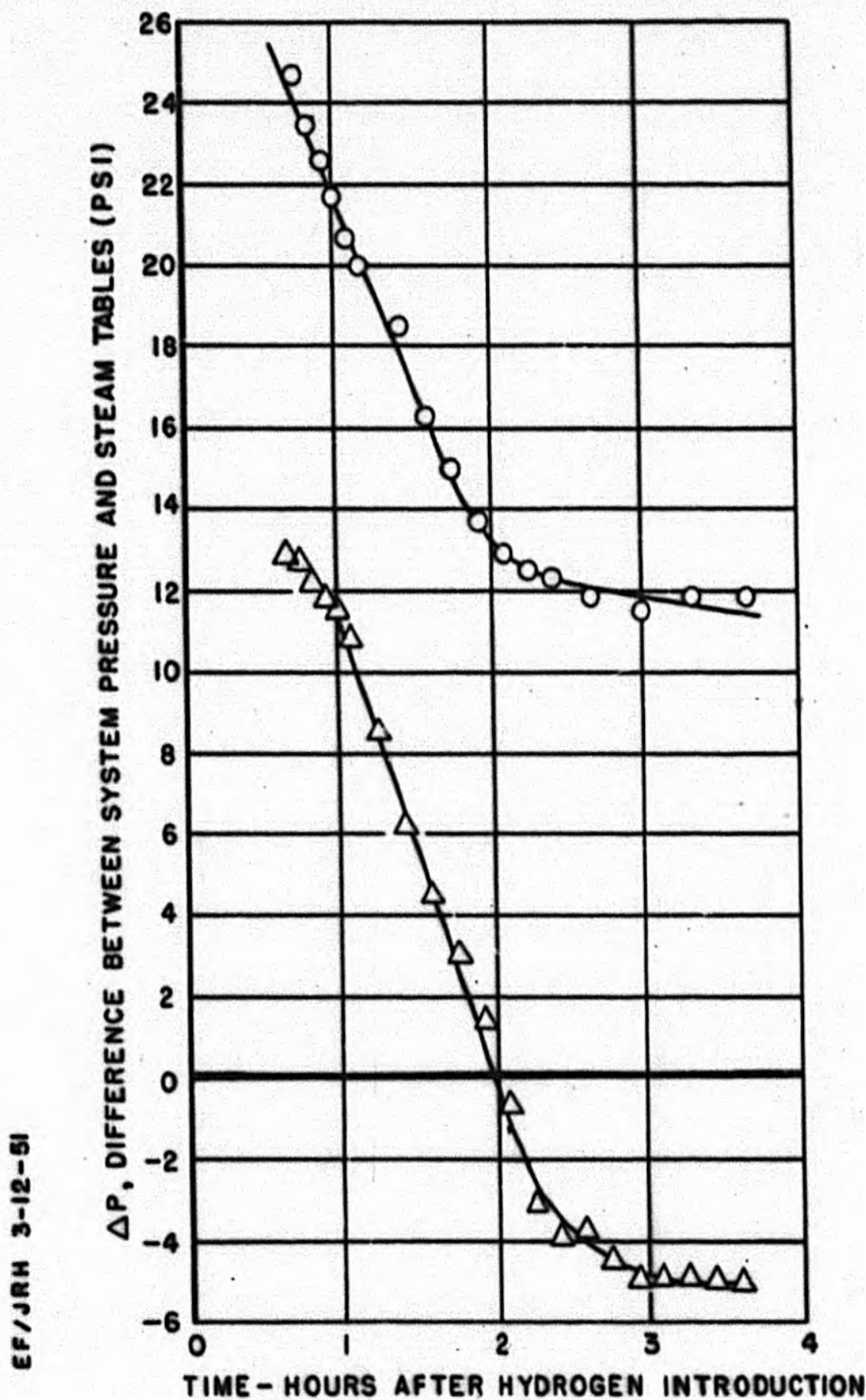

